\title{
Temporal Experience and Metaphysics
}

\section{Graham Peebles}

\author{
University of Genova \\ Department of Philosophy \\ Geneva \\ Switzerland \\ peeblesgraham@gmail.com
}

Article info

CDD: 153.753

Received: 01.03.2017; Accepted: 13.03.2017

DOI: http://dx.doi.org/10.1590/0100-6045.2017.V40N1.GP

Keywords
Perception
Temporal Perception
Time
Representationalism

ABSTRACT

The well-known phenomenological argument draws metaphysical conclusions about time, specifically about change through time and the resulting passage or flow of time, from our temporal experience. The argument begins with the phenomenological premise that there is a class of properties which underlies our experience of time and change through time, and its conclusion is that these properties are not merely experienced but exemplified. I argue that the phenomenological argument is best served by the adoption of a representational theory of perception. I then present a representational theory of temporal experience.

\section{Introduction}

Consider a visual experience of, for example, a bird in flight. It is commonly held that the motion of the bird is presented to you within one visual experience, just as the bird's shape and colour are. One does not need to infer that the bird is in motion-that it changes its location through time. The temporal phenomenon of the bird's change in location is presented to you within one experience, just as the atemporal

Manuscrito - Rev. Int. Fil. Campinas, v. 40, n. 1, pp. 145-182, jan.-mar. 2017. 
phenomenon of the bird's variation in colour is (imagine the bird is black with an orange beak). We have, then, two examples of direct perceptual experience of similar phenomena; similar enough, indeed, that we use the same term "change" for them in natural language (a familiar example: "The poker changes in temperature from one end to the other"). The experience of the change in colour, however, is one of the mere variation of colour properties across spatial extension. Among philosophers who defend dynamic theories of time, it is held that experience of the bird's change in location is not just experience of mere variation across time but of a type of what we could call real change. This real change-change through time-is a fundamentally different type of change from mere variation. Although real change involves variation over time, mere variation does not suffice for real change. Rather, this real change requires a change of time itself as we pass from future to present, and to (more and more) past. That we perceptually experience this real change is (one formulation of) what I will call the phenomenological premise of the phenomenological argument. The phenomenological argument begins with the premise that we have experience of real change and concludes that the properties experienced when we experience real change are exemplified. Whether or not these properties are exemplified is fundamental to a major question in metaphysics, namely whether or not time passes or flows.

Whether or not time passes has long been a central question in the literature. Likewise the problem of analysing our perceptual experience of temporal passage, how it works, and what constitutes it. This paper concerns both of these questions. In $\$ 3$, I will outline a representational theory of the experience of real change and hence temporal passage. The representational theory I present has two interesting features. First, it is minimal and requires only the acceptance of representationalism, a widely held theory of perceptual experience, in addition to the phenomenological premise. Second, it is compatible with all four of the propositions in the allegedly inconsistent class that together comprise what is known as the paradox of temporal awareness. All other theories deny one of these propositions, each of which is independently intuitive and plausible. Further, this representationalist framework allows for the construction of a plausible formulation of the phenomenological 
argument which invokes popular theories of the metaphysics of representational states to move from mere experience of real change to an ontology which includes the properties which underlie this real change. The phenomenological argument requires careful formulation, especially in response to recent objections in Paul (2010). I discuss this at length in $\$ 2$. In the remainder of this section, I will outline the metaphysical background in $\$ 1.1$ and the background to the phenomenological premise in $\$ 1.2$.

\subsection{Temporal Metaphysics}

The debate in this area is too vast and complex for adequate summary here. I will proceed on the following basis. I accept the psychological claim that time does indeed perceptually seem to pass or flow, and that the phenomenology of this involves a type of change that is not present across spatial variation. This has been the dominant view in the literature on the phenomenology of temporal experience at least since William James, who famously noted that 'awareness of change is ... the condition on which our perception of time's flow depends' (1890: 621). Building on this psychological claim, it seems to me that a good case can be made that Mac'Taggart's A-properties provide the correct theoretical apparatus to capture the phenomenological difference between the temporal and non-temporal aspects of experience. The subject of this paper requires the acceptance of this premise and I will defend it from some recent attacks and clarify it further in \$1.2. In this section, I will outline why I believe that the best characterisation of this phenomenological difference is in terms of McTaggart's A and Bproperties.

McTaggart's (1908) A and B-properties are mutually exclusive candidates for the properties which fundamentally explain the ordering of the time series. The A and B-orderings are identical, and the question is whether the A-properties are fundamental and entail the B-properties or whether there really only are B-properties. The A-properties are the properties of past, present, and future, and the B-properties are the properties of before, simultaneous-to, and after. A-properties are tensed properties, as opposed to untensed B-properties. An A-ordering of the 
time series is dynamic. The class of events which is present, where this is constituted by the class of events which exemplify the property of being objectively present or now, changes as time passes. The current present class gives way to the new present class when time moves on from the current present to the now future present, and the current present class becomes past, and so on. The B-series ordering, in contrast, is static. All events eternally exemplify the same temporal properties. The B-ordering is modelled on spatial variation. On this view, although the extension of events in the series is through time and not space, there is nothing dynamic about B-change in the same way as there is nothing dynamic about spatial property variation. No events ever change any temporal properties. The B-series is static, as space is, and our talk of such things as temporal passage and temporal change is given an untensed semantics. We retain this talk at the superficial level of ordinary language, but it is no longer understood to entail anything like passage, regardless that this is the way that we superficially conceive of it. What may be called a type of change through time-i.e. variation - is a feature of the B-theory, but this is a fundamentally different type of change from the type of change that the A-theory posits.

A-properties have often been conceptually linked to real change, and real change in turn to the passage or flow of time. But the relations between the three notions are controversial among A-theorists. Some deny that A-properties entail change and passage, others deny that change and passage entail A-properties. ${ }^{1}$ The only entailment between

1 A static A-world is one where the time series is ordered by A-properties but
time is frozen or static. Thus, it is allegedly possible that there could be A-
properties but no passage or flow or real change in such a world. Consider the
following analogy, however. If the time series is ordered by A-properties but
happens to be frozen, then it seems to me that there is no more a genuine lack
passage entailed by the possibility of this world than there would be a lack of
universals entailed by the possibility of a world in which there happened only to
be only a single particular. If objects are instances of universals then that there is
possibly a world in which there is only one object and thus we would not need
to posit universals were we to confine our inquiry strictly to describing this
world and its contents, does not imply that were we to inquire as to the
metaphysics of properties in this world we would not conclude that this single Manuscrito - Rev. Int. Fil. Campinas, v. 40, n. 1, pp. 145-182, jan.-mar. 2017. 
any two of the three that is universally accepted among A-theorists is that if there is real change, then there is passage. The converse is disputed by those who hold to a type of passage but deny that there is any real change involved in this. Such views involve the acceptance of the block universe, the thesis that all events are laid out in the time-series eternally and therefore that time does not unfold. The most popular version of this view holds that the time series is ordered by B-properties. However, on the passage-involving version of the block universe there is more to the relations which order the time-series than McTaggart's Bproperties. One may hold, for example, that the ordering relations intrinsically flow or are directed between their terms but without this involving change as on the A-theory (see Maudlin 2002, Deng 2013, Mozersky 2015, Oaklander 2014, 2015 for variations of this view). These views are relatively new, and pose a problem for the arguments considered in this paper. On the view there is a passage-like quality-a quasi flow, one could say-to the relations which order the time series which is not present on the B-theory. Thus, if one could experience this quality then it may seem that time flows or passes, even though as these are not A-relations it does not really flow or pass. This is something of a niche view, at least at the moment, and my remarks here will be brief. B-

particular is to be analysed in terms of universals. We would ask ourselves what we would say were there two objects. Something similar is true for a hypothetical static A-world. Although there is no actual passage in such a world, it does not follow that this world does not entail that there could possibly be passage. And it is the theoretical category of A-properties that allows us to capture this possibility. In holding that the time series is ordered by Aproperties, we have what we need to account for the possibility of passage and that is all that is required for the entailment between A-properties and passage. According to the notion of absolute becoming, the passage of time and the change involved therein need not involve a change in one event becoming past when it was previously present in the way posited by the A-theory, but rather it being replaced by a numerically distinct event with numerically distinct elements. This can be seen as passage and real change-time does flow or pass and things therefore change in a way that they do not across space-without A-properties. Absolute becoming, though, is something of a niche view, and I will not discuss it here.

Manuscrito - Rev. Int. Fil. Campinas, v. 40, n. 1, pp. 145-182, jan.-mar. 2017. 
relations are already directed from before to after. So whatever the relation is that orders the series on this view, it must be more than directed in this sense. The proponent of the view now faces a dilemma. Either this reduces to something which is compatible with the B-theory and explains why the time-series is ordered from before to after, such as causation or entropy for example, or it does not. If the former, then this is a standard B-theory. If the latter, then it seems unclear what theoretical role the new quality is playing. It does not seem to explain anything, or play any theoretical role except for explaining phenomenology. But if it explains only phenomenology, then this seems to gives us little reason to accept the view. Why would there be such qualities to these relations if all that they do is explain our phenomenology?

So let me set aside these theories and the metaphysical disputes raised in note 1 . I will argue that the best way to characterise our temporal experience is in fact in terms of A-properties, and given that Aproperties cannot be conceptually reduced to B-properties, the version of the phenomenological argument that I will formulate is an argument for the exemplification of A-properties. And this, subject only to these few objections, entails that there is real change ${ }^{2}$ and temporal passage or flow. This is what McTaggart thought about the relation between Aproperties and these notions, and I believe that he was correct. I will not address any further metaphysical questions that arise for the A-theory (i.e. which of presentism, the growing block, etc. is correct). I am concerned here with the phenomenological argument that moves from a phenomenological premise to a metaphysical conclusion. Thus, I am concerned initially with how things seem and then with how things may be on the basis of how they seem. And how things seems to us, as I will now argue in $\$ 1.2$, is well captured in terms of McTaggart's A-properties.

\footnotetext{
2 I occasionally say "change" instead of "real change" below. If an ambiguity should arise from this regarding whether "change" means real change as opposed to mere variation, context should make the correct disambiguation clear.
} 


\subsection{The Phenomenological Premise}

The phenomenological argument begins with the phenomenological premise that we have experience of real change or passage and moves to the metaphysical conclusion that the properties that underlie this are exemplified. Clarity about the phenomenological premise is crucial. Most importantly, the phenomenological difference between the experience of real change and spatial variation cannot reduce merely to the difference between an experience of temporal and spatial variation. A formal statement of the phenomenological argument will help to draw this out. I take the following version from Paul (2010), whose rebuttal of it I will discuss in detail in $\$ 2$.

(1) We have experiences of the nowness of events.

(2) We have experiences of passage (and of change).

(3) The thesis that there are temporal properties of nowness and passage

provides the only reasonable explanation of why we have these experiences.

(4) The thesis that there are temporal properties of nowness and passage provides

the best explanation of why we have these experiences.

(5) Hence, there are temporal properties of nowness and passage (2010: 333-359).

(1) is a statement of the phenomenological premise, and I will treat it as equivalent to (2) for the reasons outlined in \$1.1. To characterise temporal experience in terms of the contrast merely between spatial and temporal variation would not suffice. Were the difference between the experience of temporal change and spatial variation to be analysed in terms of a difference in experience pertaining only to variation through time as opposed to across space, then one could only draw from experience that there is variation through time and across space. Further, to characterise the contrast in some way that could be so reduced would also not suffice. This brings into sharp relief the relevance of McTaggart's distinction between

Manuscrito - Rev. Int. Fil. Campinas, v. 40, n. 1, pp. 145-182, jan.-mar. 2017. 
$A$ and B-properties. A-properties cannot be analysed in more fundamental terms. A B-theorist analyses such real change out of the metaphysical picture, and so any characterisation of temporal experience which could submit to such an analysis could not motivate the phenomenological argument. The phenomenological argument requires clarification with an additional supporting premise such as (6).

(6) The terms in which experience is characterised in (1) and (2) cannot submit to a reductive analysis in B-terms.

Premise (6) is necessary as without it (1)/(2) would not support (3) and (4). This will become clear in $\$ 2$, where the fact that A-properties are conceptually basic in that they cannot be analysed in any more fundamental terms will play a substantial role in my formulation of the phenomenological argument. So, as well as rebutting the outright denial of (1)/(2), an option I will discuss presently, the proponent of the phenomenological argument must formulate (1)/(2) in terms which block this reduction.

Until recently, the phenomenological premise passed almost unquestioned in the literature, with some notable exceptions (for example, Mellor 1998, Hestevold 1990). The literature is replete with examples of this. Indeed, almost every well-known discussion of the subject-from those on both sides of the debate- has contained some acceptance of it. However, in the past few years, it has come under increased scrutiny (see, for example, the discussions in Prosser 2007, Deng 2013, Hoerl 2009, Le Poidevin 2007, Skow 2011).

As our question is not primarily theoretical but psychological, it seems that there can be quite reasonable dispute about this. We are interested in what our experience purports to tells us. I accept that we do in fact experience the passage or flow that occurs when things undergo real change. If our experience is of more than mere temporal variationis of more than mere duration-then the proponent of the phenomenological argument has the initial foothold that they require. Frischhut draws out the tactic that I will consider for formulating it.

To experience temporal passage by virtue of experiencing change,

Manuscrito - Rev. Int. Fil. Campinas, v. 40, n. 1, pp. 145-182, jan.-mar. 2017. 
a subject would have to experience $\mathrm{A}$-change as $A$-change, rather than B-change, for A-change (as opposed to B-change) only occurs if time passes. In other words, for the folk intuition to be correct, a subject's experience of change would have to consist in more than simply experiencing $\mathrm{F}(a)$ at $\mathrm{t}_{1}$ and $\mathrm{G}(a)$ at $\mathrm{t}_{2}$. The folk intuition, however, is just that we experience passage by virtue of experiencing A-change rather than B-change. Although some Atheorists do argue along these lines, it should be noted that this is a different argument altogether. Our everyday experience of change is silent on whether time passes or not (2015: 149).

But that we experience passage or flow by experiencing A-properties is, it seems to me, precisely the argument that the proponent of the phenomenological argument will make. When I reflect on my experiences, for example, the way that change through time seems is well-captured in terms of McTaggart's A-properties. What more there is to our experience of change through time as opposed to variation across space seems to me to be well-captured by the notion that what was present and is now past really was present and is now past.

I accept that careful attention to one's experiences does reveal that the phenomenology of the experience of change across space and through time is different in the important, fundamental way that the phenomenological argument requires. It is not the case that the difference in these experiences can be reduced to merely the same type of change (i.e. mere variation) across space and through time. The phenomenological difference between experience of change through time and variation across space is just that: things merely vary across space, but they really change through time. There are two axes of phenomenological difference here, the extension across which things vary/change and the way in which they vary/change. Change through time-real change - does not look like mere temporal variation. This is a merely psychological claim, but it is one that is widely shared and seems to me to be correct.

And when we analyse this difference in the ways that these phenomena are experienced, we arrive at McTaggart's distinction between $\mathrm{A}$ and $\mathrm{B}$-properties. Thus, the $\mathrm{A}$ and $\mathrm{B}$ properties are a good analysis of the way that things seem. Were experience of B-properties, 
then experience would be different. Just as our example bird seems to have black feather and an orange beak, so it seems to us that as it flies through the air it changes position in a different way than it varies in colour across its spatial extension. It seems to us that it was there and is now there in the way that McTaggart's A-properties capture. Real change, passage, or flow, are just as much features of the way that the world seems as colour and spatial extension are. To characterise matter differently would be to characterise experience incorrectly. ${ }^{3}$ Indeed, given the reductive representationalism I will assume in $\$ 2$, when we introspect experience we are really examining the world not the contents of our own minds and so to characterise experience incorrectly would be to characterise features of the external world incorrectly.

A common argument against the phenomenological premise is that it must be mistaken for the reason not that we do not, but that we could not have experience of the objective present or the now, and hence of real change or passage, because the objective present or the now could not be a feature of experience even if it were to exist. Mellor (1998) argues that experience does not mark the time of its objects, only in a sense the time of the experience itself. If I look through a telescope, what I might see, for example, may be a star in the state it was many

${ }^{3}$ Why accept that the phenomenological difference between change through time and spatial variation is best captured in terms of A-properties and not some other difference between change through time and change across space? Some possible alternative suggestions for the difference in the way that change/variation across space and through time seem are: that space has three dimensions but time only one; that change can occur in only one direction in time but more in space; that each temporal point can only be occupied once whereas each spatial point can be occupied repeatedly; and so on. However, let me ask you to focus on the experience of change, not the medium in which things change or vary. It does seem to me that change qua change through time just looks different than spatial variation. Experiencing space as having three dimensions and space two, for example, is an experiential difference, but it does not account for the difference between the experience of temporal change and spatial variation. It accompanies this difference, but does not constitute it. At any rate, this is how things seem to me and so I accept the phenomenological premise. 
millions of years ago. Nothing in such an experience would mark this fact about the state in the way that, say, the colour phenomenology of experience marks the colours of things. It is therefore only from our undergoing the experience itself and not its object or content that we can derive from experience any notion of the temporal order of things. As all experiences are present when they are undergone, all experiences therefore have the same temporal implications. A conclusion that could be drawn from such an argument is that experience either has no temporal content at all, or that it can at most present all its contents as present. However, as we do directly experience change and hence more than time (see §3) this must be mistaken.

A different conclusion from such an argument could be that all that experience tells us is that one event precedes another. Imagine I look through a powerful telescope and see two objects colliding. I then look through a second telescope and see a qualitatively identical scene. Unbeknownst to me, the first scene was of two comets colliding some time ago, and the second merely a computer simulation of such an event. As the experiences are identical, both must have the same temporal content. Yet one experience was of an event that happened long before the other. That this is not reflected in the phenomenology of the experience is shown by the fact that I would be unable to tell which experience is which. If this is the argument, then I agree with Almang's (2014) rebuttal that all that this shows is that if experience is of Aproperties then experience can be illusory. And from this we cannot conclude that experience is not of A-properties. But what the argument in fact shows is that experience is of the relative temporal properties of their contents, and this alone does not tell us whether these contents are A or B-contents.

Implicit in such an argument, I think, is another argument. According to this argument, if something is part of the content of experience it must be 'phenomenally contrastable' (see Frischhut, Skow, Hestevold). Yellow, for example, is phenomenally contrastable in that if something is not yellow, then its colour phenomenally contrasts with yellow. Again, Almang points out the weakness in this argument. According to the phenomenological premise, some elements of the content of experience are represented as past. Thus, there is a phenomenal contrast between

Manuscrito - Rev. Int. Fil. Campinas, v. 40, n. 1, pp. 145-182, jan.-mar. 2017. 
past and present. However, even if this were not so-even if experience was only of the present and one could not phenomenally contrast the present with something else in the way that one imagines doing with, say, something yellow and something blue-the reading of the phenomenal contrast argument invoked here is flawed.

I am assuming a representational theory of perception (see $\$ 2$ ). According to this theory, the phenomenology of experience supervenes on its content. Thus, if some property is in the content of experience then it has a phenomenology. The phenomenal contrast argument seems to proceed under the assumption that B-properties and A-properties are not phenomenally contrastable in the sense that two experiences which differed only in this element of their contents would be indistinguishable. On the representational view, however, this is incorrect. For two properties are phenomenally contrastable simply in virtue of being different properties in the content of experience. These properties are not obviously phenomenally contrastable in the way that, say, yellow and blue are. But they are nevertheless phenomenally contrastable in that were two experiences to have identical contents except that one features A-properties and the other B-properties, then the two experiences would have a different phenomenology. ${ }^{4}$ The supervenience of phenomenology on content secures this. An instructive analogy might be to consider a variation on Peacocke's (1983) famous example against this supervenience. Peacocke discussed the way that two trees which are the same size but different distances away are visually represented as being the same size, but the closer tree still "looks bigger"-a phenomenological difference that does not supervene on the content that pertains to the size of the tree. The rejoinder is that the phenomenological difference supervenes on the content that pertains to the distance that the tree is located away from the perceiver as well as its size. The closer tree does not look larger but closer (assuming there is no illusion). Consider an experience of two trees where one is twice the size of the other but twice the distance away and compare it to an experience

${ }^{4}$ I have heard the objection that this is not so, that some elements of the content may be, so to speak, "phenomenologically silent". I reject this as I believe that all aspects of experiential content are phenomenologically salient.

Manuscrito - Rev. Int. Fil. Campinas, v. 40, n. 1, pp. 145-182, jan.-mar. 2017. 
of two trees of the same size and distance away as the former tree. On the view of experience suggested by those who believe in sense-data, for example, two such experiences would be indistinguishable in this respect. But, of course, such experiences would not be indistinguishable. The reason is that in the former experience the larger tree would look to be both larger and further away (assuming no illusion). On a sense-data view of experience, such differences are not phenomenologically manifest as the spatial relations between the two sense-data are identical in both cases. This view of experience, however, is wrong. The respective contents of these two experiences would differ in respect of the represented size and distance of the trees, and thus there would be a phenomenological contrast between the experienced sizes and spatial relations as phenomenology supervenes on content. One should not be seduced by the idea that the elements of experience can only phenomenologically distinguished if we are able to distinguish between the different elements of photographs taken from the point of perspective of the experience. And what goes for size and distance also goes for A and B-properties. These properties differ, and so if they are perceivable then according to representationalism they are phenomenologically contrastable.

A similar rebuttal can be given to a related argument. It is sometimes suggested that the phenomenology of temporal experience can be analysed in terms of the subsequent revealing to the subject of different B-times. Here again is Frischhut.

Just as we (standardly) occupy various spatial perspectives during our lives, we occupy various temporal perspectives during the course of our lives. Throughout our lifetime we are aware of what happens at different times, at different times-that is to say, we are aware of one time after another. But this change of temporal perspective can be explained dynamically as well as statically. Explained dynamically, our being aware of one time after another is in some sense 'brought about' by time 'moving' or 'passing by, that is, by the fact that time passes. Explained statically, we 'move' through time, changing our temporal perspectives, one by one, in a similar way as we are moving through static space, thereby changing our spatial perspectives (2015: 149).

Manuscrito - Rev. Int. Fil. Campinas, v. 40, n. 1, pp. 145-182, jan.-mar. 2017. 
I disagree that the static explanation accurately could reflect how experience is. When I experience the bird flying through the air, it looks like the bird was there and the bird is now there; that the bird was in a different place before than it is now. These temporal qualifications are properties of events involving the bird, in precisely the same way as the black experienced is a property of the bird. The temporal connections in experience are connections between events involving the bird, not essentially identical to not seeing what is in my hand at one time and then seeing what is in my hand at another time. It is not merely that something is revealed which was not revealed before. Rather, the events directly experienced are experienced as being related to each other in that one was before the other.

The relative plausibility of the phenomenological premise should be accepted and the phenomenological argument is therefore at least worth discussing. So we should accept (1)/(2). Philosophical analysis of the notions involved in the characterisation of the phenomenology in (1)/(2) at least plausibly lead us to interpret them in terms of McTaggart's Aproperties and (6) follows. Of course, experience may not be veridical, it may not in the end allow us to move from (1)/(2) to (3) and (4) and thus (5). I will now argue that, drawing on these reasons for (6), the adoption of a representational theory of experience allows for a formulation of the phenomenological argument that has not been considered before.

\section{The Phenomenological Argument}

In a recent critique of the phenomenological argument, Paul argues against premise (3). (3), she argues, does not follow from (1)/(2). I would like to stress what strikes me as a crucial point in defence of (3) and hence (5) as following from (1)/(2).

If we adopt a representational theory of perception, then (1)/(2) will be interpreted as meaning that we have perceptual representations of real change. This will then allow us to construct a version of the argument which evades objections of the type raised by Paul. If representationalism is adopted, (3) does indeed follow from (1) and (2) if 
one in addition commits oneself to some commonly accepted (although by no means uncontroversial) theses regarding the metaphysics of perceptual representation. In $\$ 2.1$, I will argue that the adoption of representationalism strengthens the argument considerably. In $\$ 2.2$, I will outline the further commitments about the metaphysics of representation involved in the way in which I formulate the argument. ${ }^{5}$

\subsection{Representationalism and Qualia}

It is necessary for a proponent of the phenomenological argument to hold that experience be analysed representationally, ${ }^{6}$ and not in terms of qualia, where a quale is a purely subjective element of experience which

${ }^{5}$ The phenomenological argument rests on the premise that we have perceptual experiences of A-properties, not that we have general, i.e. not wholly perceptual, experiences of A-properties. Implicit, then, in the argument is that there is something about perceptual experience which renders our experience of passage more likely to mean that there is passage than our belief in passage does. The adoption of a representational theory of the type outlined below explains this, and this version of the argument does not rely on a general claim about the epistemic merit of experience, but rather a very specific claim about the metaphysics of perceptual representation. I take this to be an advantage of this formulation.

${ }^{6}$ The representational theory is that the phenomenology of experience, "what it is like" to undergo an experience as it is often put, supervenes on the representational content of the experience. The representational content is the accuracy conditions of the experience, or how the experience represents or conveys matters to the subject as they undergo it. For influential defences of representationalism see Harman (1990), Tye (2000), Dretske (1995), Byrne (2001). My preferred version of representionalism is reductive representationalism, as defended by Harman, Tye, and Dretske. On this view, experiences are transparent to their contents. The properties experienced are identical to those in the content. On non-reductive representationalism, this is not necessarily so. Mere supervenience does not entail transparency, as supervenience alone does not entail that the properties which account for the phenomenology of experience are identical the properties in the content.

Manuscrito - Rev. Int. Fil. Campinas, v. 40, n. 1, pp. 145-182, jan.-mar. 2017. 
does not supervene on (is not identical to) the representational content of experience. ${ }^{7}$ Therefore the phenomenological difference between the experience of real change and mere variation will be analysed in terms of the representational content of experience. And, following my arguments about the correct characterisation of $(1) /(2)$, these contents will feature A-properties. Paul, on the contrary, argues as follows against this type of argument.

The move by the antireductionist [proponent of A-properties as a result of the phenomenological argument] is faulty because it makes a fallacious inference from temporal phenomenological oomph to temporal ontological oomph. It fails to account for the possibility that a temporal experience is simply a part of a purely phenomenological experience and nothing more. But a temporal experience is just a part of an overall phenomenological experience and nothing more (2010: 341).

The underlying claim here is that the phenomenology of real change and passage does not really constitute any experience of real change, passage, or A-properties in the sense that it would do were it a representation thereof, but is 'merely phenomenological'. A natural way to understand a view like this-unless one holds with Paul that experience has no such features and that we are in error not about what our experience tells us but about how our experience is-is that it is merely a quale that experience has which gives it this impression. A quale with oomph, to use Paul's term. This ought to be resisted by the proponent of the phenomenological argument. For if these experiences are purely phenomenological then we do not have experiences of

\footnotetext{
${ }^{7} \mathrm{I}$ am setting aside discussion of the direct realist theory on which perceptions are relations not to representational contents but to objects or states of affairs. A formulation of the argument in these terms would be equivalently strong with respect to establishing (5). However, such an argument runs into greater difficulties than the representational version. Specifically, it is not clear that the direct realist theory can help itself to a metaphysics of experience which is as strong and as well worked out as those invoked in \$2.2. If they can then the argument presented here can be reformulated in direct realist terms.
}

Manuscrito - Rev. Int. Fil. Campinas, v. 40, n. 1, pp. 145-182, jan.-mar. 2017. 
anything external in having them, only experiences which merely possess 'the animated character of flow or change' (2010: 334).

However, according to representationalism, at the very least the 'animated' qualia supervene on a representation of a type of change which is distinct from spatial variation. This accounts for the qualitative difference between the real change and mere variation in experience. According to reductive representationalism, we can move straight from this qualitative difference to the properties in the contents of the experiences. The qualitative difference is accounted for solely by these properties in the content. We have direct experience of different properties in having experience of real change as we do when we have experience of mere variation. This follows from the acceptance of the qualitative difference between real change and mere variation in experience and representationalism about experience.

Consider what introspection would tell us were the elements of experience that we take to be an experience of real change, passage, or flow to turn out to be non-supervening qualia. Such qualia are supposed to be introspectively recognisable as non-representational. To take a classic example of such an alleged quale, consider the blurriness in blurry vision. According to proponents of a "blur-quale", the blurriness in blurry vision can be introspected as non-representational. ${ }^{8}$ The blurriness qualifies the experience and not what the experience is of. The blur tells us nothing about anything external. Were the 'animated character' in experience like the blur in blurry vision, introspection would not tell us that we have direct experience of anything external which could be characterised in such a way. Rather, we would discover that it is only our experiences which have this purely subjective character. If so, an experience with the phenomenology that we associate, incorrectly as it would turn out, with real change, passage, or flow would not attribute these properties to anything external. There would be no external properties necessarily connected in any way to these experiences. Thus (3) and (4) would not follow from (1)/(2).

${ }^{8}$ See, for example, Crane (2008), Smith (2008).

Manuscrito - Rev. Int. Fil. Campinas, v. 40, n. 1, pp. 145-182, jan.-mar. 2017. 
So, the proponent of the phenomenological argument will resist the idea that we can capture the phenomenology in terms of qualia. Having adopted representationalism, the proponent of the phenomenological argument can now strengthen their argument. First, they will make explicit the argument that A-properties are required in analysing the phenomenology. Second, they will invoke theories of the metaphysics of representation which involve instances of the representata in the explanation of how experiences come to represent these properties at all.

Before dealing with the second move in $\$ 2.2$, let me say some more about the first. The proponent of the phenomenological argument holds that reflection on experience alone gives rise to our belief that there is real change, passage, or flow, or at least gives rise to our concept of this. ${ }^{9}$ This does not follow if the underlying phenomenology turns out to be accounted for merely by a quale. Assume a standard non-conceptual theory of representational content. ${ }^{10}$ On this theory, experiences have contents which represent the same properties as do our concepts of those properties, only the contents themselves are not composed of concepts but have as elements properties themselves. ${ }^{11}$ As I set out in $\$ 1$, I accept that the relevant experiences cannot be interpreted as having only the contents of mere variation and temporal direction or extension. This explains the phenomenological difference between temporal and atemporal change. If reflection on the contents of these experiences yielded only the difference that some experiences are experiences of time and some are of space and that there is variation through both, even if experience may seem at first that this is not so-i.e. if the perceptual contents were conceptually reducible to contents featuring B-properties-

9 If one adopts a conceptual theory of perceptual representation, then this argument will be even quicker as experiences will feature our very concept of real change. For a prominent (but since recanted by the author) defence of conceptualism, see McDowell (1994).

10 See Tye and Dretske for defences of representational nonconceptualism.

${ }^{11}$ This is the standard understanding, and I will assume it although there is some discussion about the correct formulation of nonconceptualism. See Crowther (2006), Speaks (2005).

Manuscrito - Rev. Int. Fil. Campinas, v. 40, n. 1, pp. 145-182, jan.-mar. 2017. 
then the B-theorist could immediately dismiss the phenomenological argument just as they could immediately dismiss it were the phenomenology of experience to turn out, in fact, to be accounted for by a quale. ${ }^{12}$ This shows the importance of premise (6) which I introduced in $\$ 1.2$. The proponent of the phenomenological argument needs to fend off the B-theorist both at the psychological stage and then at the further metaphysical stage of the argument. ${ }^{13}$

A-properties are not conceptually reducible to any further properties. They are conceptually basic in this way. We cannot build A-notions from more conceptually fundamental notions. This makes A-properties basic in the way that, say, the property of being a bouse is not. The property of being a house reduces to more fundamental properties. Of course, there is a great deal of argument about what we can really say in the end about these matters in general. However, there is a clear way in which Aproperties are basic in the sense that they cannot be constructed from more fundamental properties. For this is precisely what is at stake in the debate between A and B-theorists. B-theorists do not reduce Aproperties to more fundamental properties, they eliminate them. Atheorists introduce A-properties precisely because we need new fundamental properties to account for the concepts in terms of which we analyse the contents of our experience over and above the resources that B-properties provide.

12 Note also that we must hold the A-properties do not enter the contents of our experiences via cognitive penetration. For a better explanation of experience of A-properties than there actually being A-properties may be that we make a conceptual mistake which results in experience of A-properties. See Seigel (2011) for general discussion of this issue.

${ }^{13}$ Of course, many B-theorists argue that A-properties are incoherent or result in a fatal regress. And this was McTaggart's original argument. However, resolving this obviously exceeds the scope of this paper. If, indeed, this turns out to be the case, then the argument presented in this paper is flawed at some point and would obviously have to be withdrawn. While the coherence or acceptability of A-properties is a live question, however, I feel that the arguments presented here are worth consideration.

Manuscrito - Rev. Int. Fil. Campinas, v. 40, n. 1, pp. 145-182, jan.-mar. 2017. 
With these elements in play, consider a version of the phenomenological argument that proceeds in the following four steps. First, we adopt representationalism about experience. We can take this to be established by prior, independent argument. Second, our experience of real change, passage, or flow is accounted for by the presence of Aproperties in the contents of experience. We can take this to be established by reflection on the phenomenology of our experiences. Third, A-properties are conceptually basic in the sense that they cannot be reduced to more fundamental properties. We can take this to be established by metaphysical reflection. We could now take a fourth step. We could introduce the argument that metaphysics of perceptual representational states involves instances of some of the properties represented in experience in the explanation of how states come to represent these properties at all. Due to their being conceptually basic, A-properties will be among these properties. The argument, then, would look like this.

(1) We have experiences of the nowness of events.

(2) We have experiences of passage (and of change).

(6) The A-properties in which experience is characterised in (1) and (2) cannot submit to a reductive analysis in terms of Bproperties (they are conceptually basic).

(7) Experience is representational.

(8) Instances of conceptually basic properties explain the capacity of the perceptual system to represent those properties.

(3) The thesis that there are temporal properties of nowness and passage

provides the only reasonable explanation of why we have these experiences.

(4) The thesis that there are temporal properties of nowness and passage provides

the best explanation of why we have these experiences.

(5) Hence, there are temporal properties of nowness and passage

(1) and (2) are established by introspection (and must be accepted for the whole discussion to get off the ground). (6) is established by 
metaphysical argument regarding the properties that correctly characterise the experiences in (1) and (2). (7) is established by prior independent argument. I will discuss (8) in \$2.2. Thus, (3) and (4) and hence (5) follow.

\subsection{The Metaphysics of Representation}

In order to draw out the background to (8), consider again Paul's argument. Even if experience is representational, and the phenomenology of experience is not to be accounted for in terms of qualia, this does not show that there are A-properties. The B-theorist could proceed as follows.

the reductionist [objector to A-properties] should deny the inference from our experience as of change to the existence of passage. To do this, she should explain how our experiences as of change could derive from our cognitive reaction to the successive replacement of properties - but in a universe without passage ... What needs to be shown is how experience as of change does not require some sort of empirical detection of passage (2010: 346).

The strategy Paul is discussing is to divorce the phenomenology from 'empirical detection' of passage. She points out that, for example, the same phenomenology can arise in cases where we know that there are no such properties to be detected. She uses the colour-phi phenomenon as an example. When two differently coloured circles at the opposite ends of a screen flash on and off alternately at a high enough rate, we undergo the illusion that there is a single circle which is moving. She continues as follows.

Just as the cognitive science suggests, the brain processes the series of inputs and produces a mental representation or experience as of $O$ changing in some suitably animated or flowing way from being $P$ to being $Q$. More generally, when we have an experience as of passage, we can interpret this as an experience that represents inputs from earlier and later temporal stages and simply "fills in" [note omitted] the representation of motion or of changes. Thus, according to the reductionist, there

Manuscrito - Rev. Int. Fil. Campinas, v. 40, n. 1, pp. 145-182, jan.-mar. 2017. 
is no real flow or animation in changes that occur across time. Rather, a stage of one's brain creates the illusion of such flow, as the causal effect of prior stages on (this stage of) one's brain (2010: 352).

if the brain can create the illusion of flow in cases of apparent motion, then it can create the illusion of flow in cases of experiences as of passage ... just as the series of frames of $<$ red dot flash, left side $>$ and < green dot flash, right side $>$ are static inputs that create an experience as of change in color and an experience as of a persisting dot moving from the left to the right side, the series of temporal stages in which $O$ is $P$ and in which $O$ is $Q$ are static inputs that create an experience as of change from $O$ being $P$ at $t_{1}$ to $O$ being $Q$ at $t_{2}$ (2010:353).

The tactic would be to show that there are example cases in which we undergo experiences with the phenomenology we associate with flow but where we know that there is none. Hence, we know that the brain can create this phenomenology in a way which does not rest on 'empirical detection'. Paul's argument is fallacious if it is interpreted as attempting to show that we do not perceive flow. That we are sometimes deceived in this way does not show that we are always deceived. However, Paul is not giving an argument of this fallacious form. Rather, she situates the argument within a wider debate in which she considers that the other arguments favour those who reject A-properties. The phenomenological argument is, so to speak, "the last argument standing", and she aims to undermine it. Although her argument does not by itself show that it is invalid, it strengthens the opponent's hand by providing an empirically backed explanation of our ability to undergo experiences with the phenomenology we associate with flow in cases where we know that there is none. Hence, with the background that the other philosophical arguments favouring the opponents of A-properties are to be dismissed, we are reasonable in rejecting it in the light of these observations. Naturally, if this is one's view, one may then want to invoke qualia in accounting for the phenomenology involved.

However, a representationalist proponent of the phenomenological argument will hold, first, that there is a genuinely experiential phenomenology of real change, and, second, that the elements of 
experience with the phenomenology of real change, passage, or flow, are representations of A-properties. And this would not merely be a defensive manoeuvre. Someone who accepts (1)/(2), (6), and (7) can now invoke (8). They can argue that in order to represent some properties in experience, instances of these properties will feature in the explanation of how it is that we have acquired the capacity to visually represent these properties at all. They can invoke one of the leading theories of the metaphysics of perceptual representation which explains how a perceptual state comes to have the representational content that it does by appealing to instances of the represented property in the explanation of the development of the perceptual system's capacity to represent that property at all.

Which properties will these be? Clearly we experience some properties for which this is not true. People can hallucinate dragons, for example. These properties will be properties we experience (which we do not infer from experience and which do not arise from cognitive penetration) which cannot be built up from more fundamental properties of which we are directly aware (such as, for example, the property of being a dragon is built up from more fundamental properties). Whatever the full range of these properties is (colour is one obvious candidate) it quite plausibly includes A-properties. A-properties are experienced-they are neither inferred nor, we assume, arise from cognitive penetration - and they are conceptually basic and therefore cannot be 'built up' from other properties. What is now in question is the very possibility of perceptually representing A-properties at all.

Theories of representation which follow the template set by Stampe's (1977) causal co-variation theory have the features required to play a role in such an argument. ${ }^{14}$ According to this basic template, that experiences represent the properties that they do is explained by an explanatory causal relation between instances of those properties and the experiences which represent them. Likewise, for example, for Fodor's asymmetric dependence theory, where the causal condition is supplemented by an appeal to asymmetric determinacy of misrepresentation on accurate

${ }^{14}$ See also Dretske $(1981,1988)$.

Manuscrito - Rev. Int. Fil. Campinas, v. 40, n. 1, pp. 145-182, jan.-mar. 2017. 
representation. ${ }^{15}$ Another recent causal co-variation theory is Tye's (2000) theory whereby the representational content is fixed by what would cause the representational state in optimal conditions. Similarly, also, for Dretske's later indicator semantics, which again involves representata standing in the correct causal relation to representations of them. Any teleological theory on which experiences serve the function of picking out instances of the properties that they represent will also fall into this category. ${ }^{16}$ If one such theory is correct, and A-properties are experienced and are conceptually basic, then it would seem plausible that A-properties are among those for which the explanation of how it is that we can experience these properties at all involves instances of these properties. To survey the vast literature in this area, however, would fall outside the scope of this paper. The central point that I would like to stress is that a representationalist can appeal to one of these theories in formulating the phenomenological argument. Once (6) and (7) are accepted in addition to (1)/(2), the door is open to (8).

There is one immediate objection that must be noted, however. Some have argued that the truthmakers for tensed propositions or sentences are untensed facts. ${ }^{17}$ One could perhaps then extend this argument in such a way as to undercut the tactic I have suggested for formulating the phenomenological argument. Perhaps B-properties can feature in the causal explanation of how our perceptual states come to have Acontents, just as, according to this argument, A-propositions can have Btruth-conditions. This seems to be a promising line of attack, but I think that one could not transition immediately from the argument that the truthmakers of tensed propositions or sentences are untensed to conclude that the argument presented here is flawed. It would have to be shown that one can transition such an argument about semantic relations into an argument about causal relations which are metaphysically prior to semantic relations - that the argument can be modified to an argument

${ }^{15}$ See, for example, Fodor (1987).

${ }^{16}$ See, for example, Millikan (1984), Papineau (1984).

${ }^{17}$ See Mellor (1988), Paul, (1997). Smith (1993) and Craig (1999) oppose this argument. See also Dyke (2003).

Manuscrito - Rev. Int. Fil. Campinas, v. 40, n. 1, pp. 145-182, jan.-mar. 2017. 
that B-properties can feature in the causal relations which explain the contents of experiences in such a way as to render the contents as $A$ representations of B-properties. And there will be a significant difficulty here that I can foresee. Consider, for example, a theory in which the property which regularly or dominantly causally co-varies with (the tokens of) a type of representational state is the property that is represented by that state. Perceptual representations are transparent to the representata according to reductive representationalism. If the dominant cause of the type $F$-representing experiences is property $F$, and $F$-representing experiences have their contents fixed by causal relations holding between instances of $F$ and tokens of the type F-representing experience, then if these causal relations were to be held fixed but the property that features in them changed from $F$ to $G$, the state would be of the type $G$-representing. But then experiences would then be transparent to the objects which are $G$, not $F$. Hence, as our actual experiences represent $A$ and not B-properties and experiences are transparent to their representata, one would wonder how it is that B-properties could play the correct causal role. If Bproperties featured in these causal relations, should it not be that we experience B-properties and not A-properties?18

My purpose in this section was to clarify that the phenomenological argument is better formulated if experiences are representational. The argument presented stands as a challenge to those who object to the phenomenological argument and as an option to consider for those who favour the argument. All of the premises in the argument are independently plausible and the argument seems to me to be valid. Having set out a version of the phenomenological argument that relies on a representational theory of experience, I will now present a representational theory of temporal experience. The theory is independent of everything said above, but it is complementary and, I hope, interesting in its own right.

18 This problem is not considered in Orilia and Oaklander (2014), for example.

Manuscrito - Rev. Int. Fil. Campinas, v. 40, n. 1, pp. 145-182, jan.-mar. 2017. 


\section{A Minimal Representational Theory of Temporal Experience}

The subject matter of this paper begins with the premise that we have genuinely perceptual experience of temporally extended change. That is, our experiences range over both elements of a temporal change. Neither a second experience nor an accompanying mental state of another type, a judgement, memory, or standing belief, is required for our awareness of change. Arising from this is Miller's (1984) 'paradox of temporal awareness' which can be set out as the following four propositions.

(9) We experience only the present.

(10) The present is punctual.

(11) We directly experience real change.

(12) Real change occurs over a temporal spread - i.e is temporally extended and not punctual.

It is usually held that at least one of (9) to (12) must be rejected. ${ }^{19}$ The theory of temporal experience I will present in this section, though, is compatible with the acceptance of (9) to (12). To my knowledge, there is no other such theory.

(9) is an assumption, in need of a minor clarification in order to factor in the time-lag, ${ }^{20}$ which disallows the claim that an experience can range over more than one time. (10) is a metaphysical thesis that is rarely questioned. ${ }^{21}$ To accept (11) entails holding to Miller's 'principle of simultaneous awareness'. This principle states that in order that a change be experienced directly, and not come before the mind as a matter of

19 See Dainton (2008) for discussion and an overview of the literature on different theories of temporal experience.

${ }^{20}$ What (9) really should say is that we perceive only (what was once) a present, not the present, as the latter implies that the present that is seen is the present that is present at the same time that the experience is present. (9) is usually put in terms of "the present", however, and the slight unclarity is harmless.

${ }^{21}$ For discussion of a temporally extended metaphysical present, see Dainton (2001).

Manuscrito - Rev. Int. Fil. Campinas, v. 40, n. 1, pp. 145-182, jan.-mar. 2017. 
inference or memory, the two temporally distinct states of affairs over which the change occurs must be simultaneously before the mind within a single experience. ${ }^{22}$ As (12) states, change takes time and the two events or states of affairs involved in the change are spread over two times, whereas according to (9) our experience is only of one time.

In short, my suggestion is that as the object of experience, $x$, moves from position $p_{1}$ at time $t_{1}$ to position $p_{2}$ at time $t_{2}$, our successive visual experiences of this have the contents: $x$ is now at $p_{1} ; x$ was at $p_{1}$ and is now at $p_{2}$. 'Was' and 'now' pick out A-properties. This generalises to all real change, not just motion. In directly experiencing this change, therefore, we represent the object of the change within one experience. This theory is compatible with (9) to (12). On this view we experience present facts. One of these facts, though, is a fact about the past. To experience that $x$ was at $p_{1}$ is not for the experience to stretch into the past in any way. It need go nowhere else than the present. This accounts for (9). There is no conflict with (10), so we need not question it. The theory accounts for (11), as the change is experienced within a single experience. And we need not question (12), as the change itself takes two times. As (9) to (12) are all intuitively plausible, it is an advantage of this theory that it can be held in conjunction with (9) to (12).

Competing theories in the literature deny one of (9) to (12). Memory theories, for example, deny (11). According to memory theories, change comes before the mind as a result of two mental states, an experience and a memory of the content of the previous experience. That there is change before the subject's mind when undergoing an experience is therefore a matter of inference. Specious present theories deny (9). According to the punctual and extended versions of the specious present theory respectively, either the experience itself is punctual but takes in a

22 Miller has a second principle, the 'principle of presentational concurrence' (1984: 107), which holds that the presented events in experience must temporally unfold isomorphically to the experience of them. Acceptance of both of Miller's principles leads to theoretical difficulties. Among some others, however, Dainton (2000) accepts both, holds (10) to (12), denies (9), and holds that experiences themselves are extended over at least two times.

Manuscrito - Rev. Int. Fil. Campinas, v. 40, n. 1, pp. 145-182, jan.-mar. 2017. 
temporal spread of events simultaneously but as successive- that is, the two events unfold successively within a punctual experience-or the experience itself is temporally extended isomorphically to the temporal extension of the event which it takes in, and all contents are experienced simultaneously within the experience as it unfolds. ${ }^{23}$ The retentional theory also denies (9). On the retentional theory, the prior event is directly experienced simultaneous to the current event, but under a different temporal mode of presentation which it acquires through being 'retended' from the prior experience where it was presented not as prior to a present content but as the present content. ${ }^{24}$ The retentional theory is the theory which most resembles the one being presented here, but on this theory (9) is not denied.

All variations of the retentional theory are of the same form. An experience has two elements ${ }^{25}$ - a presentation of an event as now, or present, and a presentation of an event as preceding this present event. Broad (1938) adopted a version of this theory in reaction to criticism of his previous theory. Broad's (1923) theory was a punctual specious present theory, and, like all such theories, faced criticism in respect of the problem of simultaneous presentation of two elements as successive within a punctual experience. ${ }^{26}$ Broad's second theory moved away from specious present model towards a retentional model, and Broad elaborated on the way in which the temporal modes of the two events are presented on this model. Broad introduced the notion of 'presentedness' to account for the way in which one event seems to be temporally prior to the other even though they are both presented simultaneously. This is supposed to differ from the unfolding within a punctual experience which causes problems for the punctual specious

${ }^{23}$ See, for example, Broad (1923), Dainton (2000).

${ }^{24}$ See, for example, Husserl (1964). On this theory, there are also protentions, anticipatory elements of the experience which present the change still to come.

${ }^{25}$ Or three, if there is a protention which protends into the future in the way that a retention retends into the past.

26 See, for example, Dainton (2000), Mabbott (1951), Mundle (1954), Kelly (2004).

Manuscrito - Rev. Int. Fil. Campinas, v. 40, n. 1, pp. 145-182, jan.-mar. 2017. 
present theory.

All retentional theories have this basic form. Some element in the theory plays a role analogous to a mode of presentation of each of the two events which comprise the change, even though the elements of the theories differ. If the notion of the presentedness of the different events is interpreted in terms of different representational contents, as the analogy with the mode of presentation should suggest, then the picture becomes simple and clear. This, then, is essentially my proposal: a representational version of the retentional theory. ${ }^{27}$ This theory has a number of advantages. It is based on representationalism, a widely accepted general theory of perception. It allows for experiences to be punctual and explain how a temporal spread can be taken in, while avoiding the problem that bedevils the punctual specious present theory with respect to explaining how two simultaneous representations can account for a phenomenologically successive unfolding. Further, it is compatible with all of the four propositions in the paradox of temporal awareness, and also with the arguments in $\$ 2$ concerning the phenomenological argument.

Consider again Miller's principle of simultaneous awareness. An experience must simultaneously present the two elements of the experienced change, but it must present them as temporally distinct and so it must present a temporal spread within a punctual experience. Whether or not this results in metaphysical difficulties for other theories, it certainly does not result in any difficulty for a representational theory. I can judge, for example that my trip lasted only a weekend, or that it took me two days to get from Singapore to Buenos Aires. These judgements represent at one time a temporal span of two days without requiring that the act itself be extended, or that the act itself has any properties other

27 A representational theory has been discussed in the literature, in Tye (2003), but Tye's discussion is not extended and the theory not presented in detail. Tye's central interest in this book is in the problem of the unity of consciousness in general, and not with elucidating in detail a theory of temporal experience. See also Almang (2014) for a-very different-intentional, as opposed to representational, theory.

Manuscrito - Rev. Int. Fil. Campinas, v. 40, n. 1, pp. 145-182, jan.-mar. 2017. 
than representing this content. $^{28}$ Likewise for experiences on a representational theory.

The precise theory of the experience of change that I am putting forward is a representational theory with a tensed conjunctive content. The tensed A-contents account for the phenomenological difference between the direct experience of real change and mere variation. Consider object $x$ moving from $p_{1}$ to $p_{4}$ through times $t_{1}$ to $t_{4}$. Factoring in the time lag, which I will assume for simplicity takes one time, ${ }^{29}$ the suggestion is as follows.

\section{Time State of Affairs}

$t_{1}$
$t_{2}$
$t_{3}$
$t_{4}$ $x$ at $p_{1}$

$x$ at $p_{2}$

$x$ at $p_{3}$

$x$ at $p_{4}$

\section{Content of Experience}

$x$ is at $p_{1}$

$x$ is at $p_{2}$ and $x$ was at $p_{1}$

$x$ is at $p_{3}$ and $x$ was at $p_{2}$

This minimal representational theory satisfies the desiderata of a theory of temporal experience. We experience change on this theory, as within one experience we are presented with the change in $x^{\prime}$ s location over time in such a way as to differentiate this from the experience of mere variation. This satisfies (11). There is no conflict with (10), nor with (12). And (9) is not denied either, as the two elements of the change are present facts. Experience need not stretch into the past, but merely represent a present fact about the past.

Given that we accept (9) as a datum, it is not incumbent on me to explain why experience functions in the way I have suggested. There is

${ }^{28}$ Tye (2003: 90) notes this.

29 This brings the problem that it might make all of our experiences nonveridical as the events experienced will already be in the past by the time the experience of them occurs. But the time-lag is a general problem for theories of perception and so I will not discuss it in detail here.

Manuscrito - Rev. Int. Fil. Campinas, v. 40, n. 1, pp. 145-182, jan.-mar. 2017. 
some evidence to suggest that the visual system processes information in a way that is compatible with my suggestion. Paul, for example, appeals to the fact that 'the brain performs some sort of interpretive function when it processes sensory information ... experimental results strongly suggest that some sort of sensory processing prior to the brain's representation of motion is responsible for our experience of motion or of change' (2010: 337). And as Tye notes, 'our brains collect information a little into the future before an experience is generated, so that what we experience is in reality a little in the past, just as the "backward-looking" proposal supposes' (2003: 91). My suggestion is in effect that the visual system, so to speak, buffers the prior perceptual content and then redelivers it with a change of tense. As to why this is so, a good answer to this question would seem to be the advantage for decision making that having change through time directly experienced, as opposed to its needing to be inferred, may provide. One may worry at this point, though, that there could be no way that the fact at $t_{2}$ that at $t_{1} x$ was at $p_{1}$ could stand in the required causal relation to elicit at $t_{2}$ a perception of $x$ having been at $p_{1}$ at $t_{1}$. However, the original fact of $x$ being (then) now at $p_{1}$ could stand in the correct causal relation at $t_{2}$ to elicit a perception of this. Subsequent to the first representation, the very same information is stored and modified via a mechanism that we have no reason to hold does not preserve veridicality in virtue of the right type of causal chain holding between the initial and any subsequent experiences which represent it. This is so for memories, for example.

The elements of this theory of temporal experience are simple. First, representationalism. Second, the analysis of the differing phenomenology of direct experience of real change and mere variation in terms of the former being representations of A-properties. Third, the claim that these representations are conjunctive. There are some points, though, which require some further discussion, and there are three related objections which will immediately arise.

First, the phenomenological adequacy of this account of the experience of real change. This is analysed in terms of a tensed conjunctive content, and there are two questions that could be raised about this. The first question, using the example of motion again, is whether or not this accurately captures what it is like to experience real 
change. It only gives us the proposition that $x$ has moved, not that $x$ is moving. The second is whether, as a conjunction, the content is "direct" enough. The first question has a quick answer. Either it could be maintained that we strictly speaking do only directly experience that something has moved; or, if this does not suffice, then the theory could be easily modified to include a version of protentions. That is, the content in the example case would have the three conjuncts $x$ was at $p_{1}$, is now at $p_{2}$, and will be at $p_{3}$. And these contents could be delivered to experience as a result of a process which rests on detection of the object actually at $p_{3}$ and which delivers this content to experience a brief moment after the fact but as a protention in conjunction with the content that $x$ is now at $p_{2}$.

Second, the directness of a conjunction. Are the propositions " $x$ is at $p_{2}$ and is moving from $p_{1}$ to $p_{3}$ " \& " $x$ was at $p_{1}$ and is at $p_{2}$ and will be at $p_{3}$ ", and " $x$ has moved from $p_{1}$ to $p_{2}$ " \& " $x$ was at $p_{1}$ and is at $p_{2}$ " respectively conceptually equivalent? It seems to me fair to argue that we would not need to infer the second from the first in either case. It seems fair to say that in each case the first displays what we mean by the second. Thus, there is no need to infer the second from the first. We would not need to infer that there is, or has been, change in either case.

This theory will require an account of the 'internal clock' in order that the content of experience be specified in the correct way. The spatial locations at which the objects are experienced can be analysed in terms of the representation of their egocentric spatial location. Accounts of this are available in the literature. ${ }^{30}$ The content that I have suggested, however, also features a temporal location. But we can make the same move to distinguish their temporal location. The contents are tensed and so the current experience is the time which is represented as now. This gives us the temporal origin. There is a problem regarding how to account for the relative distance of representations of temporal location into the past. In order account for this, I propose a metric classification which qualifies the past tense contents in the following way.

When a content is delivered to experience, the first conjunct is that $x$

30 See Evans (1982), and also the discussion of scenario and scene content in Peacocke (1992).

Manuscrito - Rev. Int. Fil. Campinas, v. 40, n. 1, pp. 145-182, jan.-mar. 2017. 
is now at $p_{1}$. The subsequent content is that $x$ is now at $p_{2}$ and $x$ was at $p_{1}$. Just as the positions in egocentric space are individuated along three axes by our ability to discriminate the smallest distances along them, so perhaps we could hold that positions in egocentric time are individuated along the temporal axis our ability to discriminate the smallest distances along them. And our ability to discriminate the representations of egocentric time in experience is constrained by the experiences themselves: each experience presents only one time, the present. The second conjunct in experience represents that $x$ was at a location only one experientially discriminable time prior-i.e. one experience ago, or one unit prior in egocentric time. The second conjunct, then could be expressed as $x$ was 1 at $p_{1}$, where the metric ranking in 'was 1 ' represents that the time at which $x$ was at $p_{1}$ was only one experience ago. This model is simple and the conjunctions have only two conjuncts, but this may be an oversimplification. Perhaps, there are three conjuncts: $x$ was 2 at $p_{0}, x$ was $_{1}$ at $p_{1}$, and $x$ is now at $p_{2}$. If protentions are involved, then one conjunct will be that $x$ will $_{1}$ be at $p 3$, and so on. ${ }^{31}$

There are three related objections to this account that immediately present themselves which I will do my best to briefly deal with. One is that on a representational theory, past tense contents will not be contents that can feature in experiences, just as present tense contents cannot feature in memories. The second is that it is a memory theory in disguise. The third again concerns the conjunctive content.

The first objection seems questionable as we have agreed at the outset to hold to (11). If (11), then it is not unreasonable to hold that experiences can have past-tense contents. The second objection may at first seem more threatening. However, I think it can be disarmed in a

31 For illustration, think of experiences as old-fashioned airport-departures boards. When a content is first delivered to experience, it is delivered in the present tense: think of this as a sentence written on a departures board. When the next content is delivered, the tense of the first content flips to was 1 as the second delivered to experience, and then it flips again to was 2 as the second content flips to was 1 when the third experience is delivered and so on. This breaks down at some point and have to remember that $x$ was at a certain location a while ago as this is not represented in experience.

Manuscrito - Rev. Int. Fil. Campinas, v. 40, n. 1, pp. 145-182, jan.-mar. 2017. 
similar way. That the content features a past-tense conjunct is not enough to show that the type of state featuring this content is a memory. A representational theory is more open to this line of attack than a nonrepresentational theory. But the functional role of experience, especially with respect to action, the phenomenology of experience, the fact that experience unlike memory has non-conceptual content (if this theory is adopted), and that the content is conjunctive and the other conjunct is present-tense, provide enough grounds, I think, to resist the claim that the theory is a memory theory in disguise.

I think also that the third worry, that experiences can only have atomic contents, and the subsequent possible claim that an experience having the content $(p \& q)$ actually implies that there is an experience of $p$ and an experience of $q$, is not overly troubling. Consider the experience of a blue square. It is correct to say that there is an experience of blue and an experience of squareness. But it is equally true that there is experience of a blue square. The experience of a blue square is not worryingly indirect because we can say equally well that there is an experience of blue and an experience of squareness. I think that the claim that change being experienced in terms of a conjunction actually factors the experience out into two separate experiences would not be overly troubling even if it were to succeed. Even if one were to insist that there must be two different experiences, we would no more have to infer from $\left(x\right.$ was at $\left.p_{1}\right)$ and $\left(x\right.$ is at $\left.p_{2}\right)$ that $x$ has moved than we would from $\left(x\right.$ was at $p_{1}$ and $\mathrm{x}$ is at $\left.p_{2}\right)$.

To close, let me recapitulate. I have argued that the phenomenological argument requires a representational theory of temporal experience as no metaphysical conclusion about real change, passage, and flow can be drawn from the phenomenology of temporal experience if this is accounted for in terms of a quale. I then introduced a version of the phenomenological argument which appeals to theories of the metaphysics of representation to move from experience of real change, passage, and flow to an ontology which includes the Aproperties which underlie such experience. Finally, I offered a simple representational theory of temporal experience. The theory that I have proposed is, as far as I am aware, the only theory that is compatible with

Manuscrito - Rev. Int. Fil. Campinas, v. 40, n. 1, pp. 145-182, jan.-mar. 2017. 
all of (9) to (12).32

\section{References}

Almang, J. Tense as a Feature of Perceptual Content, Journal of Philosophy 111 (7): 361-378, 2014.

Broad, C. D. An Investigation of McTaggart's Philosophy Vol. II., Part 1, Cambridge: Cambridge University Press, 1938.

Scientific Thought, London: Routledge and Kegan Paul, 1923.

BYrne, A. Intentionalism Defended, Philosophical Review, 110 (2): 199239, 2001.

CRANe, T. Is There a Perceptual Relation, in Tamar Gendler and John Hawthorne, eds., Perceptual Experience, New York: Oxford University Press: 126-145, 2008.

Dainton, B. The experience of Time and Change, Philosophy Compass, 3 (4): 619-638, 2008.

Time and Space, Ithaca: McGill-Queen's University Press, 2001.

Stream of Consciousness, London: Routledge, 2000.

Craig, W. L. On the Truth Conditions of Tensed Sentence Types, Synthese, 120 (2): 265-270, 1999.

Crowther, T. Two Conceptions of Conceptualism and Nonconceptualism, Erkenntnis, 65 (2): 245-276, 2006.

32 I would like to thank audiences at the University of Fribourg, University of Lucerne, University of Paris, and Hong Kong University for helpful discussion of the contents of this paper, and Akiko Frischhut for comments on drafts of this paper. I would also like to thank anonymous referees. This research was initially funded by Swiss National Science Foundation Project "Intentionalitythe Mark of the Mental" (CRS111-127488) and I would like to thank them for this support.

Manuscrito - Rev. Int. Fil. Campinas, v. 40, n. 1, pp. 145-182, jan.-mar. 2017. 
DENG, N. Our experience of passage on the B-Theory, Erkenntnis 78 (4): 713-726, 2013.

DRETSKE, F. Naturalizing the Mind, Cambridge: MIT Press, 1995. Explaining Behaviour, Cambridge: MIT Press, 1998. Knowledge and the Flow of Information, Cambridge: MIT Press, 1981.

Evans, G. Varieties of Reference, McDowell, J. (ed.), New York: Oxford University Press, 1982.

DYKE, H. Temporal Language and Temporal Reality, The Philosophical Quarterly, 53 (212): 380-391, 2003.

FODOR, J. Psychosemantics, Cambridge: MIT Press, 1987.

FrischHUT, A. What Experience Cannot Teach Us About Time, Topoi 34 (1): 143-155, 2015.

Harman, G. The Intrinsic Quality of Experience, Philosophical Perspectives, Volume 4: 31-52, 1990.

HoErL, C. Time and tense in perceptual experience, Philosophers Imprint 9 (12):1-18, 2009.

Husserl, E. The Phenomenology of Internal Time-Consciousness, J. Churchill trans., The Hague: Marinus Hijhoff, 1964.

JAMES, W. The Principles of Psychology, New York: Dover, 1890.

Kelly, S. D. The Puzzle of Temporal Experience, in Kathleen Akins ed., Cognition and the Brain, New York: Cambridge University Press: 208-240, 2004.

LE PoIdevin R. The Images of Time, Oxford: Oxford University Press, 2007.

Maвbotт, J. D. The Specious Present, Mind, 64 (225): 153-167, 1951.

MCDowell, J. Mind and World, Cambridge: Harvard University Press, 1994.

MCTAggart, J. E. The Unreality of Time, Mind, 17 (68): 457-474, 1908.

Manuscrito - Rev. Int. Fil. Campinas, v. 40, n. 1, pp. 145-182, jan.-mar. 2017. 
MeLloR, D. H. Real Time II, New York: Routledge, 1988.

Miller, I. Husserl, Perception, and Temporal Awareness, Cambridge: MIT Press, 1984.

MillikAn, R. Language, Thought and Other Biological Categories, Cambridge: MIT Press, 1984.

Mozersky, M. J. Time, language, and ontology: the world from the B-theoretic perspective, Oxford University Press: Oxford, 2015.

Mundle, C. W. K. How Specious is the Specious Present, Mind, 63 (249): 26-48, 1945.

OAKLANDER, L. N. Dolev's anti-metaphysical realism: a critique, in Oaklander L. N. ed., Debates in the metaphysics of time, Bloomsbury: New York: 1-29, 2014.

Temporal Phenomena, Ontology and the R-theory, Metaphysica, (16) 2: 253-269, 2015.

A, B- and R-theories of time: a debate. In: Barton A (ed) The future of the philosophy of time. Routledge, London, 2012.

Presentism, ontology and temporal experience, Royal Institute of Philosophy Supplement, 50:73-90, 2002.

ORILIA, F. and OAKLANDER, L. N. Do we really need a new B-theory of time? Topoi 34 (1):157-170, 2014.

Papineau, D. Representation and Explanation, Pbilosophy of Science, 51: 570-572, 1984.

PAul L. A. Temporal Experience, The Journal of Philosophy, CVII (7): pp. 333-359, 2010.

Truth Conditions of Tensed Sentence Types, Synthese 111: pp. 53-71, 1997.

PeAcocke, C. Sense and Content, Oxford: Oxford University Press, 1983. A Study of Concepts, Oxford: Oxford University Press, 1992.

Prosser, S. Could we Experience the Passage of Time?, Ratio 20 (1): 75-

Manuscrito - Rev. Int. Fil. Campinas, v. 40, n. 1, pp. 145-182, jan.-mar. 2017. 
90, 2007.

Siegel, S. Cognitive Penetrability and Perceptual Justification, Nous 46 (2): 201-222, 2011.

SKOW, B Experience and the passage of time, Philosophical Perspectives 25(1): 359-387, 2011.

SMith, A. D. Translucent Experiences, Philosophical Studies, 140 (2): $197-$ 212, 2008.

Smith, Q. Language and Time, New York: Oxford University Press, 1993.

SPEAKS, J. Is There a Problem about Nonconceptual Content, Philosophical Review 114 (3): 359-98, 2005.

STAMPE, S. Toward a Causal Theory of Linguistic Representation, in French, Uehling, Wettstein eds., Midwest Studies in Philosophy 2: 263, 1997.

TYE, M. Consciousness and Persons, Cambridge: MIT Press, 2003. Consciousness, Color, and Content, Cambridge: MIT Press, 2000.

Manuscrito - Rev. Int. Fil. Campinas, v. 40, n. 1, pp. 145-182, jan.-mar. 2017. 